\title{
Data Structure Course Teaching Reform Based on CDIO
}

\author{
Meiyan $\mathrm{Fu}$ \\ Qingdao Binhai College, Shandong Qingdao Shangdong China 266555
}

\author{
Keywords: Data structure; Curriculum practice; CDIO
}

\begin{abstract}
The data structure course is important basic course of computer programming, but because some problems exist in the teaching process, to some extent affected the teaching effect of this course. And from the perspective of teaching practice, this paper puts forward some "data structure" course teaching to the existing problems and put forward to solve these problems based on CDIO teaching reform scheme. To explore face appeared in the course of a variety of teaching situation, whether can timely captured data architecture. And a detailed reform and explore the CDIO data architecture. Organic integration to the classroom to answer, for the students' learning life to bring a certain degree of activity, and the open to lay a solid foundation for their thinking.
\end{abstract}

\section{Introduction}

As the key link in computer science teaching, an important key data structure, the main is to explore the fundamental problems in science and technology of computer network on many sectors. Students learning through the subject can make its master the analysis and research data to construct the trait of computer processing, at the same time can they use this model to the appropriate selection and into the category of knowledge related to reasonable logic combination, data integration and use the corresponding calculation technique. In addition, it also focuses on the data abstract understanding of students in the cultivation of thinking, to ensure that can promote students' thinking activity, broaden its academic horizons, gain professional cultivation quality of the individual, can for the future lay a solid foundation for the absorption of the various academic specialist, buried under adequate resources. Because of the subject, however, there is a more abstract concept, and at the same time with a lot of complicated knowledge, so most of the time, the academic in contact with the course is often can't grasp well, even for the calculation of basic design and program writing point also can't catch, lack of accurate and fast, for academic use to understand the difficult point is difficult and can't understand clear.

Teaching Present Situation Analysis Through a long period of time, the survey found the task of higher engineering education in the process, relevant academic researchers found that, in addition to the master certain professional skills of students and solid academic knowledge, also need to have good team cooperation spirit and the courage to explore the action of study, to be an independent thinking and the flexibility to work by hand. Admires asks for them to adapt to the new era of fashion, all kinds of group cooperation, product research and development, the needs of the system operation. The current data structure teaching generally exist in the following several problems:

The classroom mainly depend on the textbook knowledge to teach, to rely on theoretical knowledge ignored to let the students to practice the operation, the lack of the related technical training and regulating the enthusiasm;

The classroom form a single boring, only take blindly to the teacher said, students listen to the way, as a kind of unilateral no interactive teaching methods, both't interest of students, also can't drive the classroom atmosphere active, even lagging curriculum development;

Training for students' personal quality, functions of familiar technology didn't get attention, when making individual tasks or teamwork, interpersonal communication ability is low, cannot reach the state of the smooth also less enthusiasm for learning task.

So, relative to the data structure teaching atmosphere of cultivating, it's only in the operation system under the premise of the overall transformation, can let the student get larger development 
space, let the more extensive and open mind thinking node. And get reasonable comprehensive knowledge structure and combination.

\section{The Data Structure Course Teaching Reform Based on CDIO}

The Basic Idea of CDIO 3.1. The concept of CDIO representative are: conception (Conceive), Design (Design) and implementation (Implement) and operation (Operate), it the life cycle of product research and development to the product as the carrier, to let the students can be active, rich practical spirit, organic connection between curriculum learning project. As an international and the Swedish Royal Academy of engineering at the Massachusetts institute of technology and other several universities as based on the premise of years research and development of the most accord with ideal results. Core is the guidance of its use will be sincere and professional quality and moral cultivation as the basic reference, and then the engineering design projects as guidance, to enhance the comprehensive strength of the individual lifelong learning ability (including independent thinking and practice two aspects of dominance), team cooperation ability and the standardization of the adjustment, and the ability to control as the final purpose, admires asks to let the students can be flexible open autonomy through various activities, bold, with the link between classroom perception and mutual intercourse learning project. CDIO in order to highlight the promotion of basic education system, focuses on the focus of curriculum practice, has great significance for advancing learning practice; The emphasis on individual functions, cultivate and strengthen the interpersonal communication, promote the innovation of comprehensive skills, promote students can more easily integrated into the social family.

\section{The Reform of the Teaching Methods}

Problem-Based Drive Teaching. In general, the teaching idea of data structure is quite difficult, because it's too abstract fuzzy operation way, and even give the feeling of boring to understand, therefore, most of the time, students' learning in the data structure from the outset lost interest. In order to better promote students' autonomous learning, enhance students understand topic analysis, to explore and discover the problem, at present, in the teaching process using problem-based driven teaching method course. On daily task, can explain the theme of the simplified into several aspects to: ask a question, the problem is analyzed on the basis of content, and then answer. Using the form above, can further enhance the students' thinking flexibility, broaden the students' thinking at the same time, considering the problem more clearly, at the same time, this way of teaching, and to transit from the instance data structures in computing technique. For example, when we are in class 'shortest path computation, students can use the actual examples to divergent thinking: "if you travel to the northeast three provinces, how will you travel arrangements make used compared with the minimum amount?" Let the student through this example, for simulation and analysis, the problems cited resonance, and using the related calculation program to answer, the final results, applied to the life, and on the books of knowledge on the issues.

The Teaching of Practical Oriented. More highlights practical teaching, only in this way can further enhance students' understanding of the difficult subject and interest. Although "data structure" of the teaching relatively hard, in fact as long as find the right way, to let the students learn the content of theoretical, can better eliminate pumped up students to learn.

For example, such as standardization design of parking pricing problem, suppose that a shopping mall in the parking lot is only one main entrance, undertake the task of the in and out of the vehicle, then to the parking lot access billing need to apply to the ranks and stack these two concepts to the planning. Under normal circumstances, the parking lot can accommodate $\mathrm{Z}$ car is parked, although the internal environment is not very wide, when the vehicles according to the order of the time has a parking garage, or quite enough, when the upper limit of a vehicle in the garage to $\mathrm{Z} \mathrm{m}$, late into the vehicle will be because there is no enough parking location was forced to stop waiting in the aisle, only when a car come out, can smoothly enter the corridor in the first car, also is the ranks of 
emissions, the concept of the vehicle into the stack type. And, of course, because of the limitations on the corridor, the vehicles leave, plug in the aisle or in the car to be out of the garage, to make the vehicle parking area. Usually the garage parking rules are, according to how much it stays long to establish your payment amount.

Project Teaching Method. In order to better improve the students' ability of comprehensive thinking operation, the organic integration of learned knowledge to use the real case, can use project-oriented teaching forms in order to develop. The so-called project teaching, said the teacher and the students use a complete project for operation of teaching activities. It is not only the students into a meaningful work, and make students study more targeted, in addition, you also need to students in learning, can further improve personal understanding ability and flexibility.

The Establishment of the Project. Teachers and students the basic condition for topic finalized and lesson plan planning, combined with the related knowledge, to establish the teaching plan. In teaching, it is best to imagine of the project, with reference to various functions of the software development process, and students in task allocation. Followed by the partition of the project, lets the student can take the clear train of thought to analysis solutions, on different difficulty point, and then pointed to find the answer. Deepening through class, the teacher can more comprehensive project progress to determine the next step of teaching content, when travel course to late, you can collect their students in the process of solution can't through the personal or team to solve the problem of a summary, and then communicate with each other, and finally develop into a comprehensive project of the subsidiary.

Refining Project, to Complete the Task. After the above process, in the actual theoretical teaching, the classroom can be related to project allocation and task breakdown point to quote, for different together of detailed data and solutions to make a reasonable arrangement. Well, for example, for the general use of the linear structure, this knowledge is very need to students' divergent thinking, visualize the performance management system of relatively simple. Relatively speaking, the circular structure mode of learning, the requirement for students to study is relatively high, some students in the completion of urban geography resources statistics, to a certain project analysis, data architecture into etc. also need to have an organic planning. Finally, in concluding, the class can be used in a more relaxed and natural discourse to proceed with the project overview, on purpose to solve in the name of the technique in detail, also is the operation mode of the project, you can plug in some lesson plans in the information provided, through meticulous and effective explanation, to find the ideal solution algorithm.

\section{Conclusion}

In this paper, some problems existing in current teaching of data structure will be carried on the thorough exploration, through the help of the concept of CDIO, make teaching process more simple and clear, at the same time let the data teaching ideas have a deeper explanation of reform. In addition, the related academic question the extended more rich knowledge, using collaborative learning teaching form, the abstract into concrete mode, from a certain extent guide the new ideas of teaching data structure.

For structural data, the learning process as for academic, is no longer a boring and difficult to understand the process, the concept of practicality is very strong and effective guidance and the project teaching method, bring the students' learning the innovation of the whole. Faced with higher requirements of classroom learning, students can through own autonomy, open mind, smart means to solve the problem of various disciplines, will encounter difficulties in class with teacher guidance technique to the organic planning, using the data structure characteristic, at the same time, it will drive the students in the face of all kinds of refractory topic is substitution, and divergent thinking in solving. Ultimately achieve the biggest purpose of teaching effect. 


\section{References}

[1] Taoyongfang, shang hui, CDIO of higher engineering education innovation enlightenment [j] China's higher education, 2006 (11)

[2] Hongxia, Wang Guang, software engineering based on CDIO teaching mode reform and research [j] science and technology of China expo, 2009

[3] Lu, guang-jing xiong, lin-lin Chen, the design of engineering education reform idea [j] higher engineering education research, 2007

[4] Guo Jinshan, zhang wei, the data structure of classroom teaching research and practice [j] machinery management development, 2007 (10) 